\title{
Solution-based synthesis routes to thermoelectric $\mathrm{Bi}_{2} \mathrm{Ca}_{2} \mathrm{Co}_{1.7} \mathrm{O}_{x}$
}

A. Sotelo ${ }^{1}$, Sh. Rasekh ${ }^{1}$, M. A. Madre ${ }^{1}$, E. Guilmeau ${ }^{2}$, S. Marinel ${ }^{2}$, J. C. Diez ${ }^{1}$ 1 Instituto de Ciencia de Materiales de Aragón (CSIC-Universidad de Zaragoza), Ma de Luna, 3. 50018 Zaragoza, Spain.

${ }^{2}$ CRISMAT Laboratory, UMR 6508 CNRS-ENSICAEN, 6 Bd. Maréchal Juin, 14050 Caen cedex, France.

\begin{abstract}
The synthesis of $\mathrm{Bi}_{2} \mathrm{Ca}_{2} \mathrm{Co}_{1.7} \mathrm{O}_{x}$ misfit compounds by different processing routes, i.e. classical solid-state, and two solution methods namely sol-gel via nitrates and a polymer route, has been investigated. A comparison among the final products has been performed using DTA, TGA, X-ray diffraction, scanning electron microscopy, and thermoelectric characterizations. All the samples obtained by solution synthesis show a very important increase in ZT, as compared to the solid state prepared samples, due to a significant decrease in the electrical resistivity values.
\end{abstract}

Keywords: Grain growth; Microstructure-final; Platelets; Electrical properties; Thermopower.

Corresponding author: Maria Antonieta Madre e-mail: amadre@unizar.es

Address: Dept. Ciencia de Materiales; C/Mª de Luna, 3; 50018-Zaragoza; Spain Tel: +34 976762617

Fax: +34 976761957 


\section{Introduction}

Thermoelectric (TE) materials with high energy conversion efficiency are strongly required for electric power generation mainly in terms of waste heat recovery. Thermoelectric energy conversion has been shown as an effective technology that can be used to transform thermal to electrical energy owing to the well-known Seebeck effect. This physical property allows producing electrical energy from a thermal gradient between the cold and the hot side of a thermoelectric system. The conversion efficiency of such materials is quantified by the dimensionless figure of merit $\mathrm{ZT}$, which is defined as $\mathrm{TS}^{2} / \rho \kappa$ (in which $S^{2} / \rho$ is also named power factor, PF), where $S$ is the Seebeck coefficient (or thermopower), $\rho$ the electrical resistivity, $\kappa$ the thermal conductivity, and $T$ is the absolute temperature. ${ }^{1}$ As higher ZT higher the efficiency, a performant TE material must involve, therefore, high thermopower and low electrical resistivity, with low thermal conductivity.

The discovery of large thermoelectric power in $\mathrm{Na}_{x} \mathrm{CoO}_{2},{ }^{2}$ which was found to posses a high $\mathrm{ZT}$ value of about 0.26 at $300 \mathrm{~K}$, has opened a broad research field and from this moment, great efforts have been devoted to explore new cobaltite families with high thermoelectric performances. Some other layered cobaltites, such as misfit $\left[\mathrm{Ca}_{2} \mathrm{CoO}_{3}\right]\left[\mathrm{CoO}_{2}\right]_{1.62}, \quad\left[\mathrm{Bi}_{0.87} \mathrm{SrO}_{2}\right]_{2}\left[\mathrm{CoO}_{2}\right]_{1.82}$ and $\left[\mathrm{Bi}_{2} \mathrm{Ca}_{2} \mathrm{O}_{4}\right]\left[\mathrm{CoO}_{2}\right]_{1.65}$ were also found to exhibit attractive thermoelectric properties. ${ }^{3-7}$ The crystal structure is composed of two different layers, with an alternate stacking of a common conductive $\mathrm{Cdl}_{2}$-type $\mathrm{CoO}_{2}$ layer with a twodimensional triangular lattice and a block layer, composed of insulating rocksalt-type (RS) layers. Both sublattices (RS block and $\mathrm{Cdl}_{2}$-type $\mathrm{CoO}_{2}$ layer) possess common a- and c-axis lattice parameters and $\beta$ angles but different $b$ axis length, causing a misfit along the b-direction. ${ }^{8-10}$ As a consequence of their crystal structure, layered cobaltites are characterized by a very important anisotropy.

On the other hand, the preparation techniques can influence drastically the final grain size and aspect and, as a consequence, their final properties. Usually, the powders are synthesized by a classical solid state reaction method, which involves repeated mixing, milling and calcinations. Nevertheless, incomplete 
reaction, and compositional inhomogeneities are typical trademarks of conventional solid state synthesis. In this context, solution syntheses offer some advantages, as a higher precursor homogeneity and reactivity, which can result in the improvement of their properties. In this context, the aim of the present study is developing reproducible preparation methods that yield TE optimum quality of $\mathrm{Bi}_{2} \mathrm{Ca}_{2} \mathrm{Co}_{1.7} \mathrm{O}_{\mathrm{x}}$ powders for their use in shaped ceramics. This work includes a comparison of three different synthetic methods, the conventional solid-state synthesis, a sol-gel method and a versatile polymer solution synthesis route developed in our laboratory ${ }^{11,12}$ for layered ceramics. Phase development and transformation, microstructure and thermoelectric properties are discussed according to the preparation techniques.

\section{Experimental}

The initial $\mathrm{Bi}_{2} \mathrm{Ca}_{2} \mathrm{Co}_{1.7} \mathrm{O}_{x}$ powders were prepared, under air, by the following ways:

(i) Solid-state reaction: $\mathrm{Bi}_{2} \mathrm{O}_{3}$ (98\%, Panreac), $\mathrm{CaCO}_{3}$ (98.5\%, Panreac), and $\mathrm{Co}_{3} \mathrm{O}_{4}(98 \%$, Panreac) were ball-milled for 30 minutes at $300 \mathrm{rpm}$ for $1 \mathrm{~h}$. The resulting mixture was placed in a furnace and heated slowly to $750^{\circ} \mathrm{C}$, where it was kept for $12 \mathrm{~h}$, followed by furnace cooling. After cooling, the remaining powder was ground and heated again at $800^{\circ} \mathrm{C}$ for $12 \mathrm{~h}$, milled and uniaxially pressed at $250 \mathrm{MPa}$ in form of bars $\left(\sim 3 \times 3 \times 14 \mathrm{~mm}^{3}\right)$. Finally, the compacts were sintered at $800^{\circ} \mathrm{C}$ for $24 \mathrm{~h}$, with final furnace cooling.

(ii) Sol-gel: $\mathrm{Bi}\left(\mathrm{NO}_{3}\right)_{3} \cdot 5 \mathrm{H}_{2} \mathrm{O}$ ( $\geq 98 \%$, Aldrich), $\mathrm{CaCO}_{3}$ (98.5\%, Panreac), and $\mathrm{Co}\left(\mathrm{NO}_{3}\right)_{2} \cdot 6 \mathrm{H}_{2} \mathrm{O}(98 \%$, Panreac) were suspended in distilled water. Concentrated $\mathrm{HNO}_{3}$ (analysis grade, Panreac) was added dropwise into the suspension until it turned into a clear pink solution. Citric acid (99.5\%, Panreac), and ethylene glycol (99\%, Panreac), were added to this solution in the adequate proportions. Evaporation of the solvent was performed slowly in order to decompose the nitric acid excess, which allows the polymerization reaction between ethylene glycol and citric acid, forming a pink gel. ${ }^{13}$ The dried product was then decomposed (slow self combustion) by heating at $350^{\circ} \mathrm{C}$ for $1 \mathrm{~h}$. The decomposed solid was mechanically ground for 30 minutes and calcined at 750 and $800^{\circ} \mathrm{C}$ for $12 \mathrm{~h}$, with an intermediate grinding. As for the solid state 
reaction, sintering was performed, following uniaxial pressing, at $800^{\circ} \mathrm{C}$ for $24 \mathrm{~h}$ with furnace cooling.

(iii) Polymer solution synthesis: To a suspension of $\mathrm{Bi}\left(\mathrm{CH}_{3} \mathrm{CO}_{2}\right)_{2}(99.99+\%$, Aldrich), $\mathrm{Ca}\left(\mathrm{CH}_{3} \mathrm{CO}_{2}\right) \cdot 2 \mathrm{H}_{2} \mathrm{O}\left(99 \%\right.$, Panreac) and $\mathrm{Co}\left(\mathrm{CH}_{3} \mathrm{CO}_{2}\right)_{2} \cdot 4 \mathrm{H}_{2} \mathrm{O}(98 \%$, Panreac) in distilled $\mathrm{H}_{2} \mathrm{O}$, glacial acetic acid (ACS Reagent, Panreac) was added until a pink clear solution was formed. Polyethylenimine (PEI) (50\% aqueous, Aldrich) was added to the above solution which turned darker immediately due to the nitrogen-metal bond formation. After partial evaporation $(\sim 80$ vol. \%) of water and acetic acid in a rotary evaporator, the concentrated solution was placed onto a hot plate until a very dark pink paste appeared. Further heating turn this paste to violet colour, followed by a slow combustion with the release of brown fumes (nitrogen oxides). The resulting powder was milled and calcined at 750 and $800^{\circ} \mathrm{C}$ for $12 \mathrm{~h}$, with an intermediate milling, uniaxially pressed and sintered for $24 \mathrm{~h}$ at $800^{\circ} \mathrm{C}$ with a final furnace cooling.

The structural identification of all the samples was performed by powder XRD utilizing a Rigaku D/max-B X-ray powder diffractometer (CuK $\alpha$ radiation) with $2 \theta$ ranging between 10 and 70 degrees. In order to characterize the phase evolution, DTA-TGA analyses were performed in a TA Instrument (SDT Q600) system between room temperature and $900^{\circ} \mathrm{C}$. Apparent density measurements have been performed on several samples for each synthetic method using 6.35 $\mathrm{g} / \mathrm{cm}^{3}$ as theoretical density (corresponding to the $\mathrm{Bi}_{1.68} \mathrm{Ca}_{2} \mathrm{Co}_{1.69} \mathrm{O}_{7.38-\delta}$ compound $^{14}$ ). IR spectroscopy in ATR mode has been performed on samples extracted after each processing step in a Bruker IFS 28 Spectrometer, between 600 and $1800 \mathrm{~cm}^{-1}$ to determine the extent of calcium carbonate decomposition. Microstructural observations were performed on polished samples using a Zeiss SUPRA 55 scanning electron microscope fitted with energy dispersive spectrometry (EDS) analysis. Micrographs of these samples have been recorded to analyze the different phases and their distribution. From these pictures, an estimation of the amount of the different phases, have been performed using Digital Micrograph software. Transversal fractured surfaces were observed in a JEOL 6000 SEM microscope in order to evaluate their grain shape and size. 
Steady-state simultaneous measurements of resistivity and thermopower were determined by the standard dc four-probe technique in a ZEM-3 apparatus (Ulvac-Riko) between 50 and $650^{\circ} \mathrm{C}$ under partial $\mathrm{He}$ atmosphere. The heat capacity and thermal diffusivity were analysed using Netzsch DSC 404C and Netzsch model 457, respectively. The thermal conductivity $(\kappa)$ was calculated using the product of apparent density, thermal diffusivity and the heat capacity.

\section{Results and discussion}

\subsection{Precursors characterization}

DTA-TGA measurements have been performed (in air) on initial mixtures of solgel and polymer methods. Fig. 1 represents the weight loss percentage as a function of temperature for all these samples, obtained under very similar conditions. Although the samples have similar decomposition behaviour, the only significant difference is found at about $300^{\circ} \mathrm{C}$, where a broad decrease of the weight percentage is observed for the sol-gel decomposition procedure. This may be an indication of the higher thermal stability of the metal-PEIacetate complex, most likely related to the different type of bonding and to its decomposition path, which includes the release of $\mathrm{H}_{2} \mathrm{O}, \mathrm{CO} / \mathrm{CO}_{2}$, and $\mathrm{NO}_{\mathrm{x}}$.

The appearance of enthalpy anomalies at given temperatures in DTA experiments performed on these samples confirms the weight losses found in TGA. Mainly, and in correlation with the graph shown in Fig. 1, weight losses below $135^{\circ} \mathrm{C}$ correspond to the evaporation of the solvent from the initial solution; below $175^{\circ} \mathrm{C}$, water of crystallization is lost. Above this temperature, the behaviour of both precursors differs: the sol-gel sample shows a small exothermic peak at about $300^{\circ} \mathrm{C}$ and a bigger one at about $450^{\circ} \mathrm{C}$, showing a decomposition path in two different steps, while the polymer solution sample shows only a narrow exothermic peak at $470^{\circ} \mathrm{C}$ due to the combustion of the organic materials (see insert in Fig. 1). This is indicative of a higher thermal stability of the nitrogen-metal coordination, compared with the oxygen-metal coordination existing in the sol-gel method. Above $450^{\circ} \mathrm{C}$, in both cases, there is still a considerable amount of carbonate within the samples, which starts to decompose at $600-650^{\circ} \mathrm{C}$. This is confirmed by IRTF spectroscopy, in ATR 
mode, performed in each step of the treatment and represented in Fig. 2. After burning the dry products from the sol-gel and polymer solution methods, the calcium carbonate is formed (Figs. $2 a$ and $2 b$, respectively), and identified from the IR bands appearing at about 1410 (strong), 870 (strong), and 710 (weak) $\mathrm{cm}^{-1}$. Also, as it was deduced from the TGA curves, thermal treatment performed on the burned materials at $750^{\circ} \mathrm{C}$, leads to the disappearing of the IR bands associated to the carbonates (Fig. 2c), confirming their decomposition.

\subsection{Structural and microstructural characterization}

Powder XRD patterns for samples obtained from the different synthetic methods are plotted (from 10 to $40^{\circ}$ for a better clarity) in Fig. 3. They show very similar patterns where the most intense peaks correspond to the (00I) planes of the misfit cobaltite $\mathrm{Bi}_{2} \mathrm{Ca}_{2} \mathrm{Co}_{1.7} \mathrm{O}_{\mathrm{x}}{ }^{15}$ Even if minor differences are found in weak peaks, the cobaltite phase appears as the major one, independently of the synthetic route. Peaks marked with $a{ }^{*}$ in the plot correspond to the $\mathrm{Ca}_{4} \mathrm{Bi}_{6} \mathrm{O}_{13}$ secondary phase. ${ }^{16}$

Scanning electron microscopy was performed on fractured and polished samples after the sintering procedure. The most representative of the transversal fractures are shown in Fig. 4. This micrograph clearly shows that the samples derived from the solid state (Fig. 4a) and sol-gel (Fig. 4b) precursors posses similar grain sizes, while they are bigger for the samples derived from the polymer solution method, as evidenced previously for other layered ceramics $^{17,18}$ (Fig. 4c). Moreover, the sol-gel and polymer samples show lower porosity than solid state ones. When observed at higher magnification (Figs. $4 \mathrm{~d}$, $4 \mathrm{e}$ and $4 \mathrm{f}$ ), all samples show to be composed mainly of flat platelets with sizes ranging from a mean size of $8 \times 8 \mu \mathrm{m}^{2}$ for the solid state sample, to $20 \times 20 \mu \mathrm{m}^{2}$ for the polymer solution samples, while sol-gel derived samples are in between. The total thickness of these platelets ranges between 0.1 and $0.3 \mu \mathrm{m}$ and are composed, in turn, of some very thin grains, well stacked together. Due to the inherent difficulty to determine the thickness of each individual grain by SEM observations, a qualitative estimation of their thickness has been performed from the XRD results applying Scherrer's formula, using the peak corresponding to the (005) plane. The obtained values are between 50 and $60 \mathrm{~nm}$ for samples 
obtained from solid state and sol-gel methods, and about two times bigger, 90 $\mathrm{nm}$, for the polymer derived samples. These results confirm the observations performed in Fig. 4, where the PEI derived samples show bigger grains than the other two methods.

Another difference can be pointed out from these figures: the platelets in the sample derived from the solid-state reaction method exhibit rounded corners, very different from the very sharp ones found in the sol-gel and polymer solution derived samples. For all samples, nevertheless, the platelet-grains size and shape are observed to be homogeneous throughout the whole material.

In Fig. 5, where longitudinal polished sections of the samples are displayed, three main contrasts can be found. The major phase in all samples (grey contrast) is identified by EDS as the misfit thermoelectric $\mathrm{Bi}_{2} \mathrm{Ca}_{2} \mathrm{Co}_{y} \mathrm{O}_{x}$ one, with small differences in Co content ( $y=1.60$ for the solid state, 1.62 for the sol-gel, and 1.70 for the PEI). On the other hand, solid state samples (Fig. 5a) show big white aggregates (about 18 vol.\%), which appears in the sol-gel and PEI samples in lower amounts (around 6.6 and 3.0 vol.\%, respectively) and sizes with an homogeneous distribution. This contrast, after EDS analysis, shows $\mathrm{Bi}_{5.9} \mathrm{Ca}_{4.0} \mathrm{O}_{\mathrm{y}}$ composition, confirming the results obtained from XRD (where the $\mathrm{Bi}_{6} \mathrm{Ca}_{4} \mathrm{O}_{\mathrm{y}}$ phase was identified). Finally, the last observed phases (black contrast) are cobalt oxides, except for the sol-gel derived samples where they are associated to the $(\mathrm{Bi}, \mathrm{Ca})-\mathrm{Co}-\mathrm{O}$ phase, with an approximate composition $\mathrm{Bi}_{0.1} \mathrm{Ca}_{0.6} \mathrm{Co}_{1.0} \mathrm{O}_{x}$ (close to the 349 phase).

\subsection{Thermoelectric characterization}

The temperature $(T)$ dependence of the electrical resistivity $(\rho)$ according to the synthetic method and the sintering temperature is given in Fig. 6 . As it can be easily seen, the $\rho(T)$ curves show very high values for samples derived from the solid-state method in the whole studied temperature range. Moreover, it clearly shows two different parts, from 50 to around $550^{\circ} \mathrm{C}$ with a semiconducting-like behaviour $(\mathrm{d} \rho / \mathrm{dT}<0)$, and above $550^{\circ} \mathrm{C}$ with a mettallic-like one ( $\left.\mathrm{d} \rho / \mathrm{dT}>0\right)$. On the other hand, the samples derived from the solution methods show lower resistivities than those obtained from solid state route. Furthermore, they seem 
to be nearly independent with the temperature, with less marked semiconducting or metallic-like behaviour. Between these samples, the polymer solution method always shows lower resistivity values than the sol-gel ones. The values measured at $50^{\circ} \mathrm{C}$ for the sol-gel and $\mathrm{PEI}$ samples are, approximately, 70 and $45 \mathrm{~m} \Omega \mathrm{cm}$, respectively. These values are lower than the best reported resistivities for sintered specimens, about $80-100 \mathrm{~m} \Omega \mathrm{cm}$ at room temperature, ${ }^{8}$ or for textured materials (around $60 \mathrm{~m} \Omega \mathrm{cm}$ ). ${ }^{19}$ These values can be explained by the lower amounts of secondary phases for samples obtained from solution methods, and the higher amount and size of the misfit cobaltite phase in the case of the polymer solution method, as observed in SEM micrographs (see Figs. 4 and 5).

Fig. 7 displays the variation of the thermopower as a function of temperature for the three studied methods. The samples derived from solid state synthesis exhibit comparable values than those reported elsewhere $(\sim 150 \mu \mathrm{V} / \mathrm{K})$ at room temperature. ${ }^{8}$ At this temperature, the sol-gel method induces a slight increase of S $(\sim 5 \%)$ while the polymer solution method improves it by about $10 \%$. These differences can be due to the different Co contents, as mentioned previously, which can influence the overall $\mathrm{Co}^{+4} / \mathrm{Co}^{+3}$ relationships in the cobaltite phase, depending on the synthetic route. Other factor influencing the $S$ values is the amount of oxygen vacancies, higher in the case of solution methods due to the formation of a reducing atmosphere in the organic material decomposition step, as reported previously. ${ }^{12}$ These differences on $S$ are in agreement with Koshibae's expression and the oxygen content $\left(\mathrm{Co}^{+4} / \mathrm{Co}^{+3}\right.$ relationship) in the samples. On the other hand, $S$ values converge to a final value of around 220 $\mu \mathrm{V} / \mathrm{K}$ at about $600^{\circ} \mathrm{C}$ for all the samples, indicating a thermal activated mechanism.

From the above data $S^{2} / \rho$ can be calculated at about room temperature, with values about $0.01 \mathrm{~mW} / \mathrm{K}^{2} \mathrm{~m}$ for the solid state samples, and 0.04 and 0.06 $\mathrm{mW} / \mathrm{K}^{2} \mathrm{~m}$ for the sol gel and polymer solution ones, respectively. The value obtained for the polymer method is, approximately, $50 \%$ higher than the obtained for textured materials (around $0.04 \mathrm{~mW} / \mathrm{K}^{2} \mathrm{~m}$ ). ${ }^{20}$

The evolution of the thermal conductivity with temperature is represented in Fig. 8 for each synthetic method. All the samples exhibit a decrease of the thermal 
conductivity with temperature. On the other hand, solid state samples show lower values than the sol-gel samples in all the measured temperature range, due to the lower density measured on this sample $(\sim 80 \%$ of the theoretical density for the solid state sample and $\sim 90 \%$ for the sol-gel samples). In the polymer solution synthesized samples, the $\kappa$ values are practically the same to those obtained for the solid state ones while the measured densities are higher in the polymer derived materials ( $\sim 90 \%$ of the theoretical value). This decrease in the thermal conductivity of the samples obtained by the polymer solution route can be associated with the defects produced in the crystal structure by the higher amount of oxygen vacancies, as previously discussed. In order to optimize the effect of the polymer route on the TE properties, further studies will be performed.

Finally, ZT has been calculated using $\rho, S$, and $\tau$ values and represented in Fig. 9 as a function of temperature and synthetic method. As it can be clearly seen in the graph, solution methods improve $\mathrm{ZT}$ values in all the measured temperature range. This increase is particularly important for the polymer solution samples, ranging from a factor 5 (at $50^{\circ} \mathrm{C}$ ) to more than two times (at $650^{\circ} \mathrm{C}$ ) as compared to $\mathrm{ZT}$ values measured for the solid state samples. Sol-gel samples show intermediate values between solid state and polymer methods in all the measured temperature range.

All the results indicate that the PEI synthetic route produces high quality and homogeneous powders which, when appropriately compacted and sintered, lead to ceramics with low electrical resistivity and thermal conductivity using a very simple and reproducible process. It makes this method a good candidate in the preparation of bulk ceramics for applications in thermoelectric generators.

\section{Conclusions}

A comparison of several synthesis routes of the $\mathrm{Bi}_{2} \mathrm{Ca}_{2} \mathrm{Co}_{1.7} \mathrm{O}_{x}$ phase, i.e. solidstate, sol-gel and polymer solution, has been studied. The typical solid-state method results in a relatively good quality product, but the solution methods evaluated in this study provide much higher yields of the cobaltite phase and better thermoelectric properties. Among the solution methods, the polymer- 
based one has been revealed as the most advantageous, with respect to the samples homogeneity and higher values of $\mathrm{ZT}$, compared with the other two methods. This improvement in ZT properties can be associated to the very important reduction of secondary phases as well as to the different grain shape and higher oxygen vacancies obtained with the polymer solution method.

\section{Acknowledgements}

This research has been supported by the Spanish Ministry of Science and Innovation (Project MAT2008-00429). The authors wish to thank the Gobierno de Aragón (Consolidated Research Groups T74 and T12, and Project PI154/08) for financial support and to C. Gallego, C. Estepa and J. A. Gomez for their technical assistance.

\section{References}

1. Rowe DM. In: Rowe DM, editor. Thermoelectrics handbook: macro to nano. 1st ed. Boca Raton, FL: CRC Press; 2006. p. 1-3-1-7.

2. Terasaki I, Sasago Y, Uchinokura K. Large thermoelectric power in $\mathrm{NaCo}_{2} \mathrm{O}_{4}$ single crystals. Phys Rev B 1997;56:12685-7.

3. Funahashi R, Matsubara I, Ikuta H, Takeuchi T, Mizutani U, Sodeoka S. An oxide single crystal with high thermoelectric performance in air. Jpn J Appl Phys 2000;39:L1127-9.

4. Masset AC, Michel C, Maignan A, Hervieu M, Toulemonde O, Studer F, Raveau B, Hejtmanek J. Misfit-layered cobaltite with an anisotropic giant magnetoresistance: $\mathrm{Ca}_{3} \mathrm{Co}_{4} \mathrm{O}_{9}$. Phys Rev B 2000;62:166-75.

5. Leligny H, Grebille D, Perez O, Masset AC, Hervieu M, Raveau B. A fivedimensional structural investigation of the misfit layer compound

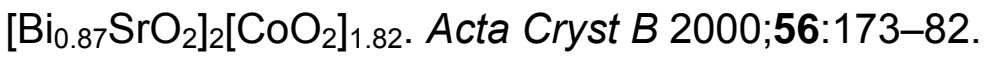

6. Maignan A, Pelloquin D, Hébert S, Klein Y, Hervieu M. Thermoelectric power in misfit cobaltites ceramics: optimization by chemical substitutions. Bol Soc Esp Ceram V 2006;45:122-5.

7. Kobayashi W, Hebert S, Muguerra H, Grebille D, Pelloquin D, Maignan A. Thermoelectric properties in the misfit-layered-cobalt oxides $[\mathrm{Bi}(2) \mathrm{A}(2) \mathrm{O}(4)]$ 
$\left[\mathrm{CoO}_{2}\right](\mathrm{b} 1 / \mathrm{b} 2)(\mathrm{A}=\mathrm{Ca}, \mathrm{Sr}, \mathrm{Ba}, \mathrm{b}(1) / \mathrm{b}(2)=1.65,1.82,1.98)$ single crystals. In Kim I, editor. Proceedings ICT 07: Twenty-sixth international conference on thermoelectrics. Korea. 2008. p. 117-120.

8. Maignan A, Hébert S, Hervieu M, Michel C, Pelloquin D, Khomskii D. Magnetoresistance and magnetothermopower properties of $\mathrm{Bi} / \mathrm{Ca} / \mathrm{Co} / \mathrm{O}$ and $\mathrm{Bi}(\mathrm{Pb}) / \mathrm{Ca} / \mathrm{Co} / \mathrm{O}$ misfit layer cobaltites. J Phys: Condens Matter 2003;15:271123.

9. Itahara H, Xia C, Sugiyama J, Tani T. Fabrication of textured thermoelectric layered cobaltites with various rock salt-type layers by using $b-\mathrm{Co}(\mathrm{OH})_{2}$ platelets as reactive templates. $J$ Mater Chem 2004;14:61-6.

10. Guilmeau E, Mikami M, Funahashi R, Chateigner D. Synthesis and thermoelectric properties of $\mathrm{Bi}_{2.5} \mathrm{Ca}_{2.5} \mathrm{Co}_{2} \mathrm{O}_{x}$ layered cobaltites. $J$ Mater Res 2005;20:1002-8.

11. Fuente GF de la, Sotelo A, Huang Y, Ruiz MT, Badia A, Angurel LA, Lera F, Navarro R, Rillo C, Ibañez R, Beltran D, Sapiña F, Beltran A. Polymer solution processing of (Bi,Pb)-Sr-Ca-Cu-O. Physica C 1991;185-189:509-10.

12. Madre, MA, Rasekh Sh, Diez JC, Sotelo A. New solution method to produce high performance thermoelectric ceramics: A case study of Bi-Sr-Co-O. Matter Lett 2010;64:2566-8.

13. Gaoke Z, Ying L, Xia Y, Yanping W, Shixi O, Hangxing L. Comparison of synthesis methods, crystal structure and characterization of strontium cobaltite powders.. Mater Chem Phys 2006;99:88-95.

14. H. Muguerra, B. Rivas-Murias, M. Traianidis, C. Henrist, B. Vertruyen, R. Cloots. Improvement of the thermoelectric properties of $\left[\mathrm{Bi}_{1.68} \mathrm{Ca}_{2} \mathrm{O}_{4}\right.$ $\delta]^{(\mathrm{RS})}\left[\mathrm{CoO}_{2}\right]_{(1.69)}$ cobaltite by chimie douce methods. J Solid State Chem 2010;183:1252-7.

15. Tanaka Y, Fujii T, Nakanishi M, Kusano Y, Hashimoto H, Ikeda Y, Takada J. Systematic study on synthesis and structural, electrical transport and magnetic properties of $\mathrm{Pb}$-substituted $\mathrm{Bi}-\mathrm{Ca}-\mathrm{Co}-\mathrm{O}$ misfit-layer cobaltites. Solid State Comm 2007;141:122-6.

16. Parise JB, Torardi CC, Whangbo M, Rawn CJ, Roth RS, Burton BP. $\mathrm{Ca}_{4} \mathrm{Bi}_{6} \mathrm{O}_{13}$, a compound containing an unusually low bismuth coordination number and short Bi-Bi contacts. Chem Mater 1990;2:454-8. 
17. Garnier V, Caillard R, Sotelo A, Desgardin G. Relationship among synthesis, microstructure and properties in sinter-forged Bi-2212 ceramics. Physica C 1999;319:197-208.

18. Garnier V, Monot I, Desgardin G. Optimization of calcination conditions on the Bi-2223 kinetic formation and grain size. Supercond. Sci. Technol. 2000;13:602-11.

19. Sotelo A, Guilmeau E, Madre MA, Marinel S, Lemonnier S, Diez JC. $\mathrm{Bi}_{2} \mathrm{Ca}_{2} \mathrm{Co}_{1.7} \mathrm{O}_{\mathrm{x}}$ thermoelectric ceramics textured by laser floating zone method. Bol Soc Esp Ceram V 2008;47:225-8.

20. Sotelo A, Guilmeau E, Rasekh Sh, Madre MA, Marinel S, Diez JC. Enhancement of the thermoelectric properties of directionally grown $\mathrm{Bi}-\mathrm{Ca}-\mathrm{Co}-$ O through Pb for Bi substitution. J Eur Ceram Soc 2010;30:1815-20. 


\section{Figure captions}

Fig. 1. TGA plot vs. temperature of the initial solutions - sol-gel; and --- polymer solution methods. The insert shows the DTA curve in the coordination compounds decomposition temperature range.

Fig. 2. FTIR curves obtained, in ATR mode, in different steps of the synthetic procedure: after burning the dry products from the a) sol-gel; and b) polymer solution method. Curve c) shows the spectra of the polymer sample after a thermal treatment at $750^{\circ} \mathrm{C}$ for $12 \mathrm{~h}$.

Fig. 3. $\mathrm{XRD}$ plots of the $\mathrm{Bi}_{2} \mathrm{Ca}_{2} \mathrm{Co}_{1.7} \mathrm{O}_{x}$ sintered specimens obtained for the different synthetic methods. a) solid state, b) sol-gel, and c) polymer solution.

Fig. 4. Scanning electron micrographs from transversal fractured samples $\mathrm{Bi}_{2} \mathrm{Ca}_{2} \mathrm{Co}_{1.7} \mathrm{O}_{\mathrm{x}}$ obtained by solid-state ( $\mathrm{a}$ and $\mathrm{d}$ ), sol-gel ( $\mathrm{b}$ and $\mathrm{e}$ ), and polymer (c and f) reaction methods.

Fig. 5. Scanning electron micrographs from longitudinal polished samples $\mathrm{Bi}_{2} \mathrm{Ca}_{2} \mathrm{Co}_{1.7} \mathrm{O}_{\mathrm{x}}$ obtained by solid-state (a), sol-gel (b), and polymer (c) reaction methods.

Fig. 6. Temperature dependence of the electrical resistivity of $\mathrm{Bi}_{2} \mathrm{Ca}_{2} \mathrm{Co}_{1.7} \mathrm{O}_{x}$ for each type of sample. $\|$ solid state; $\bullet$ sol-gel; and $\boldsymbol{\Delta}$ polymer solution.

Fig. 7. Temperature dependence of the thermopower of $\mathrm{Bi}_{2} \mathrm{Ca}_{2} \mathrm{Co}_{1.7} \mathrm{O}_{x}$ for each type of sample. $\square$ solid state; $\bullet$ sol-gel; and $\Delta$ polymer solution.

Fig. 8. Temperature dependence of the thermal conductivity of $\mathrm{Bi}_{2} \mathrm{Ca}_{2} \mathrm{Co}_{1.7} \mathrm{O}_{x}$ for each type of sample. $\mathbf{a}$ solid state; $\bullet$ sol-gel; and $\boldsymbol{\Delta}$ polymer solution.

Fig. 9. Temperature dependence of $Z T$ for the $\mathrm{Bi}_{2} \mathrm{Ca}_{2} \mathrm{Co}_{1.7} \mathrm{O}_{\mathrm{x}}$ samples prepared by the different synthetic methods. $\quad$ solid state; $\bullet$ sol-gel; and $\boldsymbol{\Delta}$ polymer solution. 
Figure 1

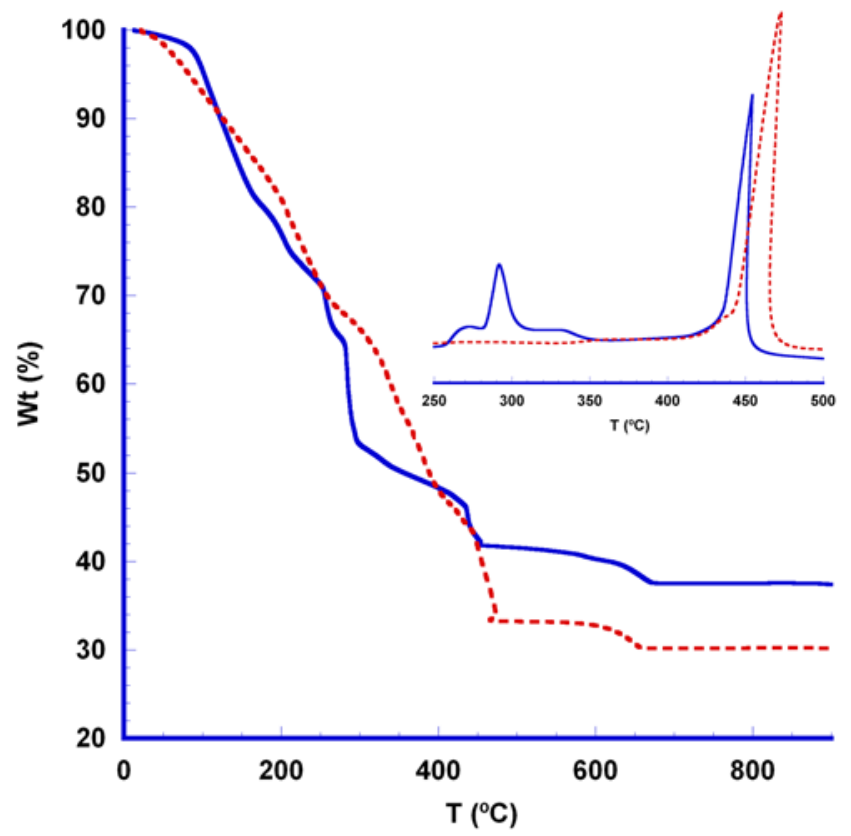


Figure 2
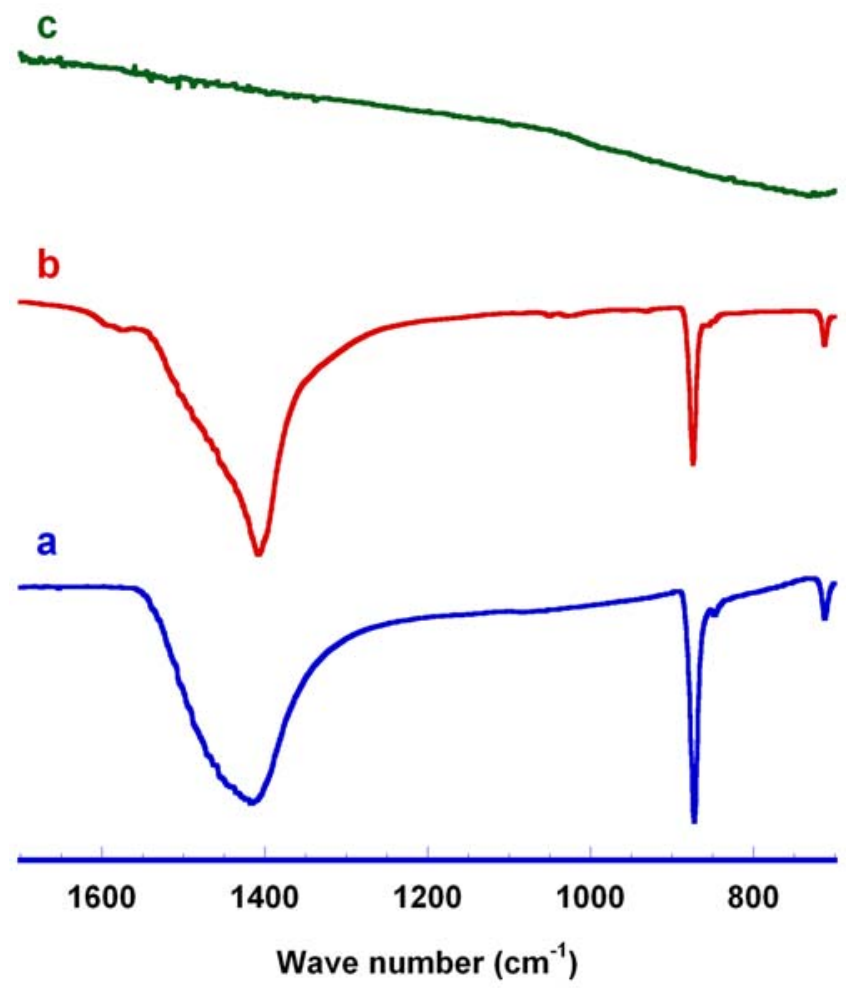
Figure 3

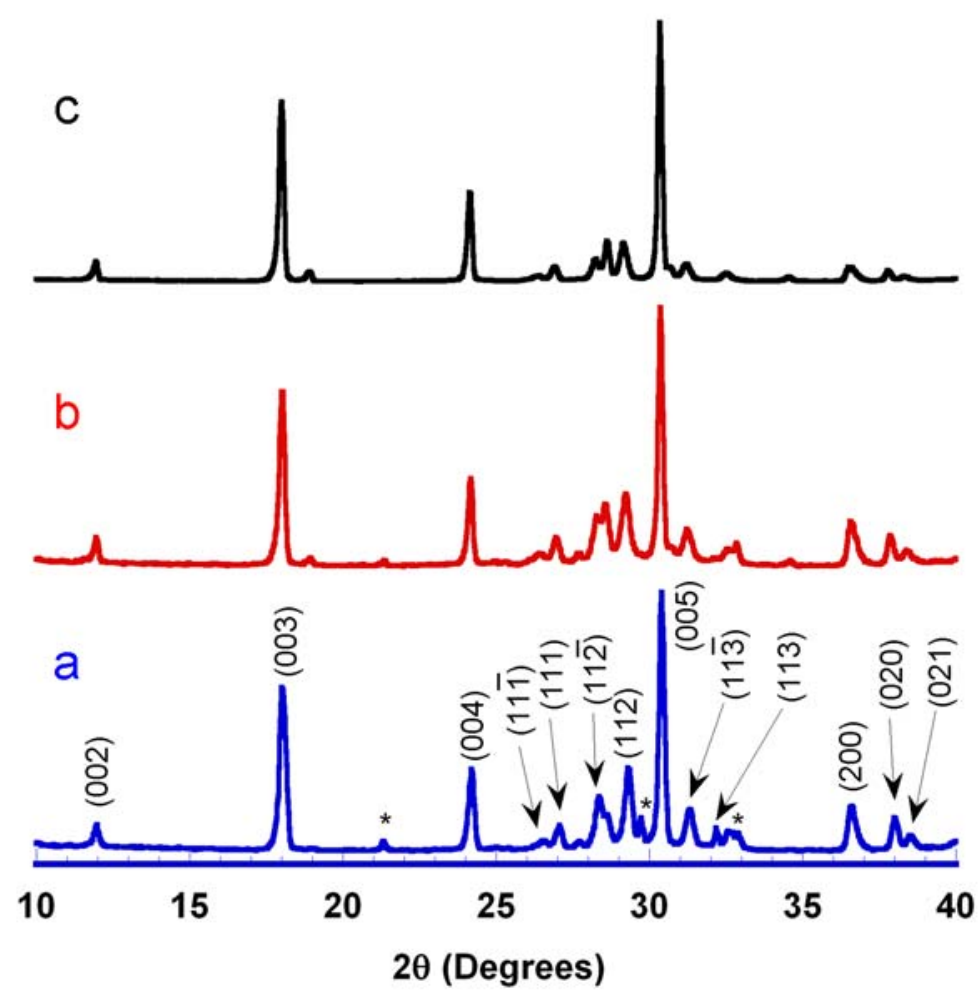


Figure 4

Figure 5




Figure 6

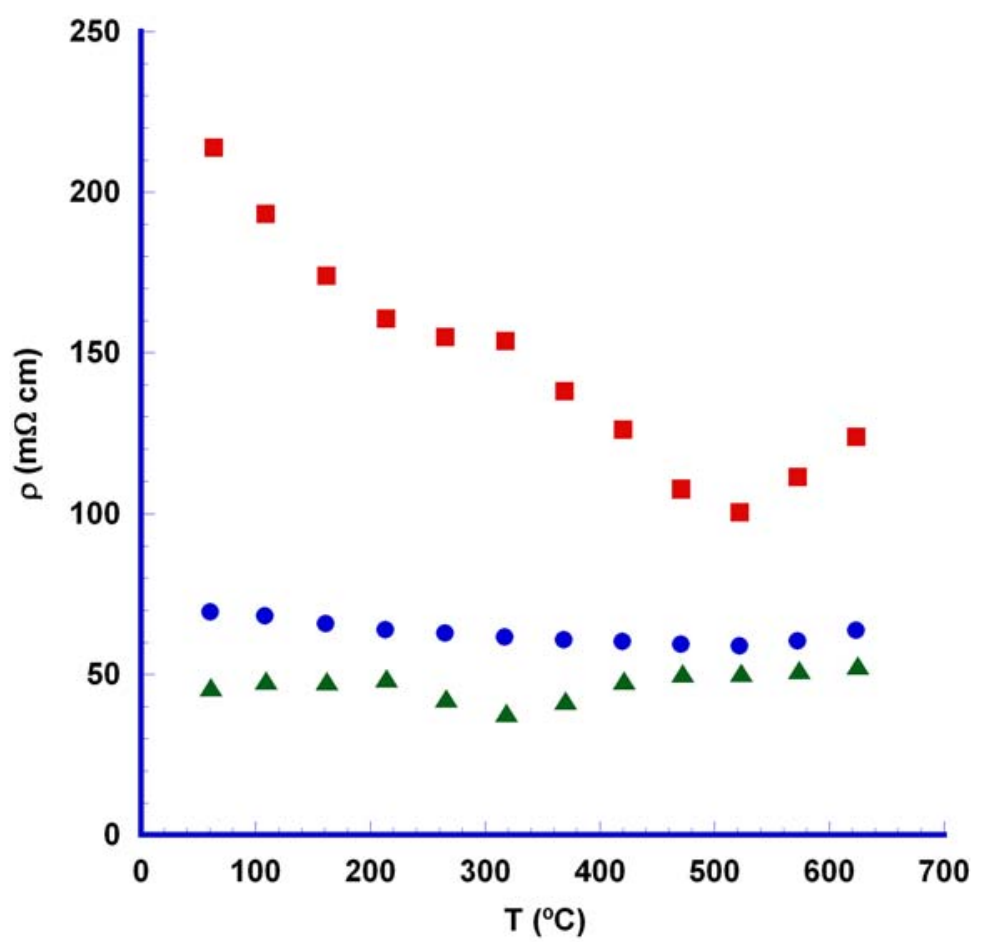


Figure 7

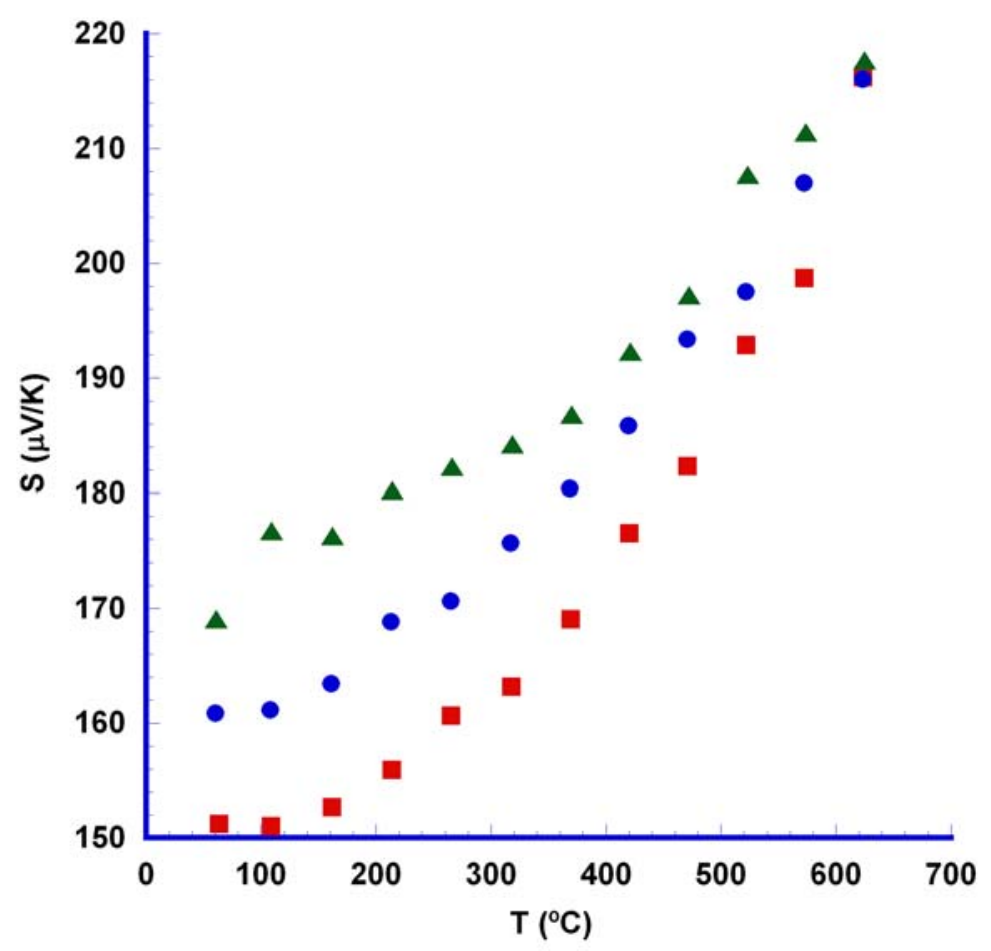


Figure 8

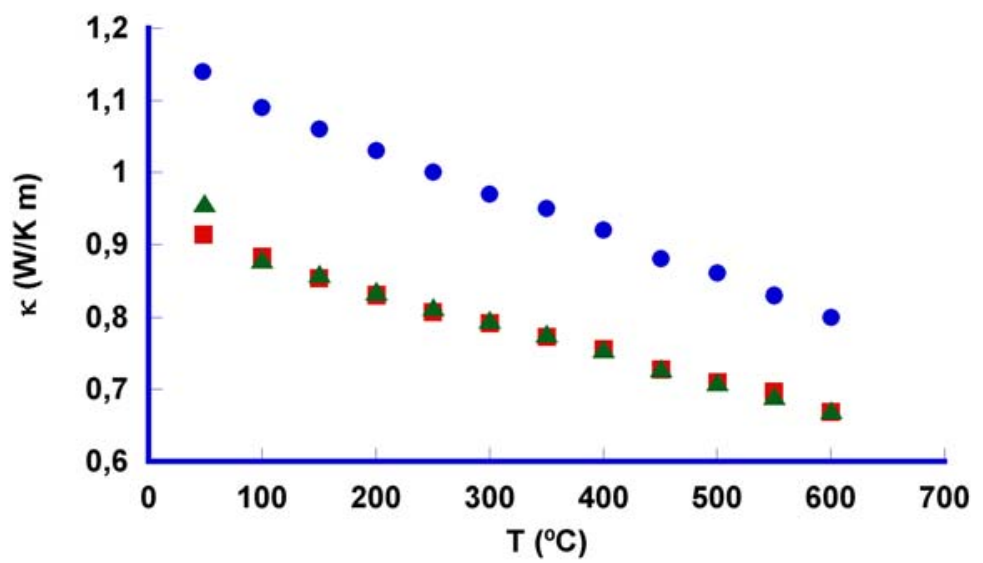


Figure 9

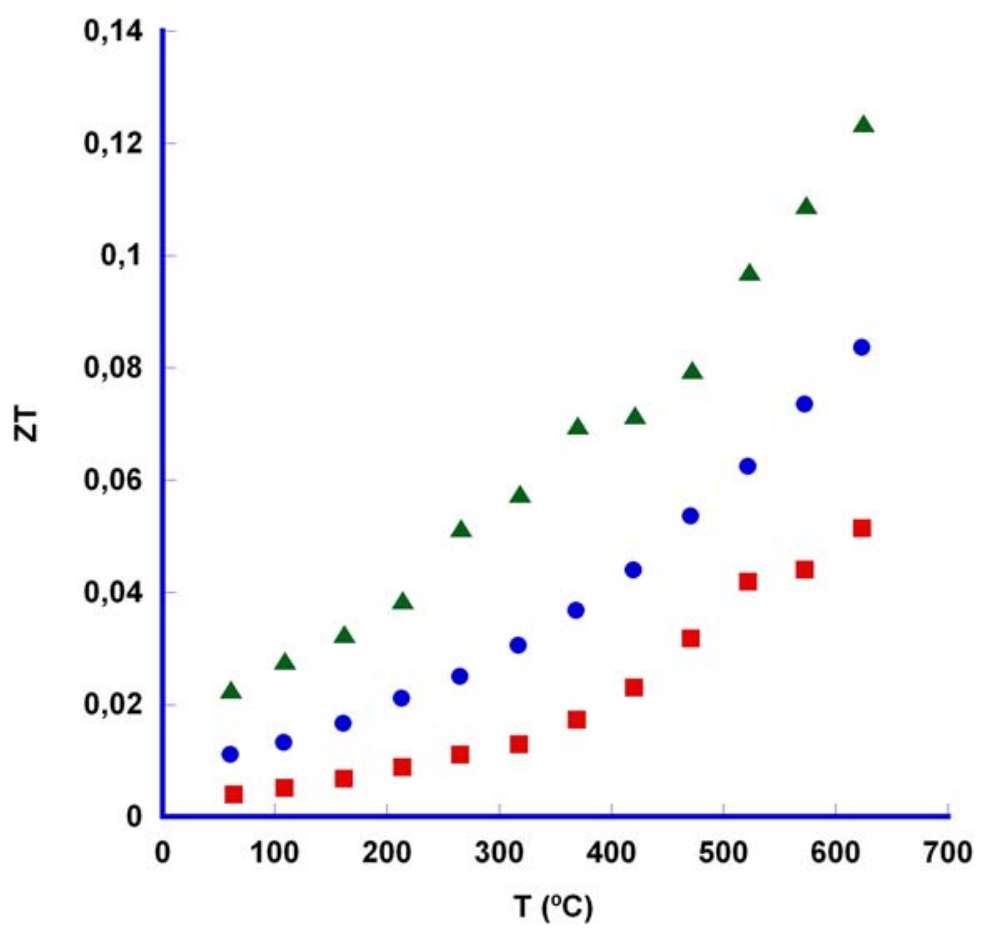

